THE PHYSICAL BASIS OF ELECTRONICS 
Distributors for the United Kingdom and Eire:

CLEAVER-HUME PRESS LTD.

(Macmillan \& Co. Ltd.)

10-15 St. Martin's Street, London, W.C. 2 


\section{THE PHYSICAL BASIS OF}

\section{ELECTRONICS}

J. G. R. VAN DIJCK

1964

Macmillan Education 
Translated from Dutch by R. H. Bathgate, Eindhoven

This book contains xiv +362 pages, 265 illustrations and two folding sheets

Other editions of this book in German, French and Dutch

U.D.C. No. 537.53

Additional material to this book can be downloaded from http://extras.springer.com

ISBN 978-1-349-81722-1 ISBN 978-1-349-81720-7 (eBook)

DOI 10.1007/978-1-349-81720-7

Original Dutch edition:

(c) N.V. Uitgeversmaatschappij Centrex, Eindhoven, The Netherlands, 1964

English edition:

(C) N.V. Uitgeversmaatschappij Centrex, Eindhoven, The Netherlands, 1964

All rights reserved

Softcover reprint of the hardcover 1st edition 1964 978-0-333-05543-4

No representation or warranty is given that the matter treated in this book is free from patent rights; nothing herein should be interpreted as granting, by implication or otherwise, a licence under any patent rights. 

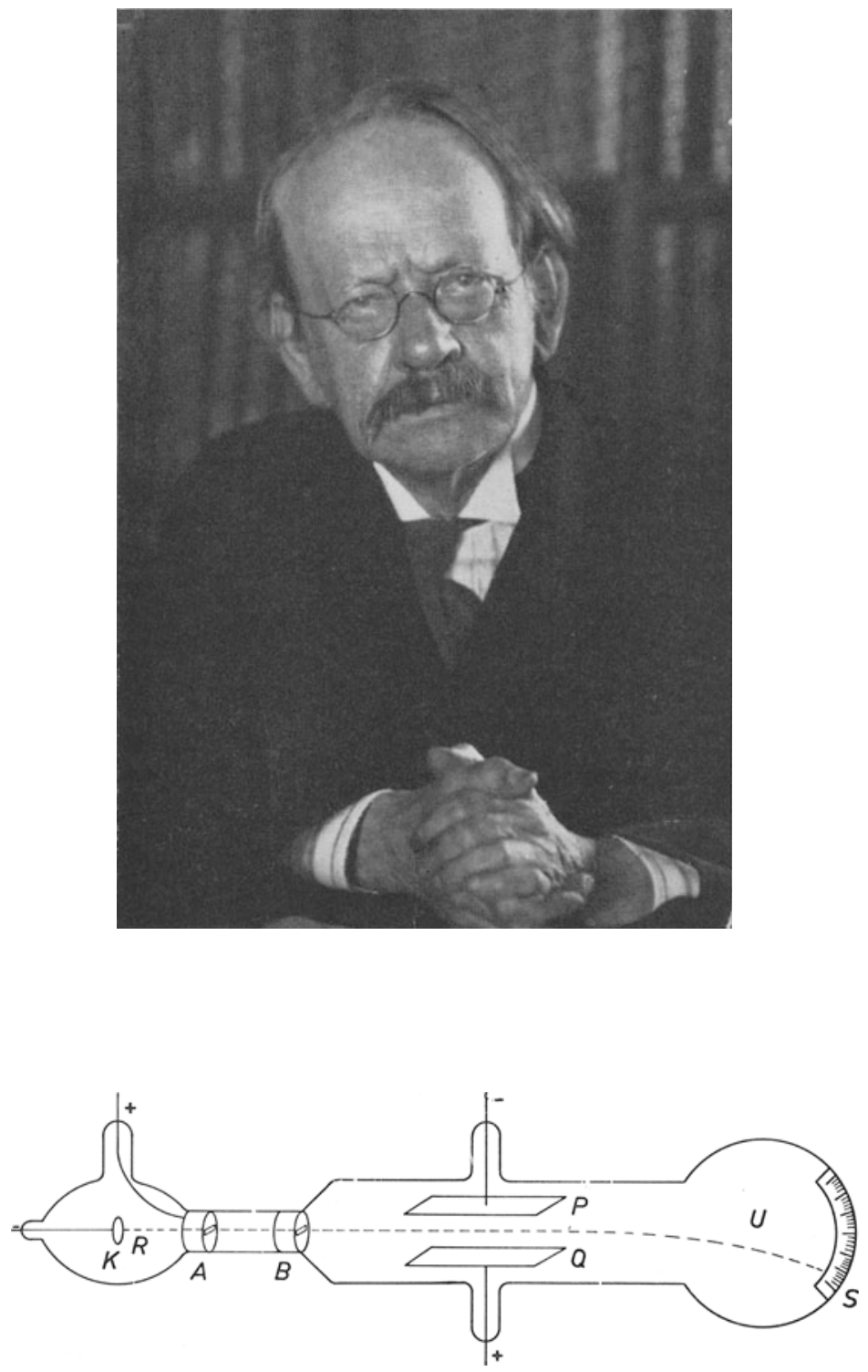

JoSEPH JoHN THOMSON (1856-1940)

who may rightly be called the "father of electronics". He demonstrated with the aid of the "electron-beam tube" shown here the real nature of this wonderful "elementary" particle, which in the last few decades has wrought such a revolution in science and industry. 


\section{PREFACE}

"For many years we have been accustomed to regard the development of electronics as an exponential process. Now, however, a much more impressive phenomenon can be discerned: it looks as if electronics is no longer content to be a branch of the science of electricity. We are witnesses today of an enormous "electronic revolution", in which what is traditionally regarded as electricity plays only a subsidiary part...."

A. Ducrocq

(in ELECTRONIQUE INDUSTRIELLE, Oct. 1961)

The education of the electronics engineer (or technician) of tomorrow may be divided into three stages: the technological, the physical, and the mathematical. In the first of these stages, the student should be introduced directly to the practical aspects of electronics (circuitry, measuring techniques) in such a way as to arouse in him real enthusiasm for the subject. This should lead him to ask spontaneously about the why and the wherefore of the many "miracles" he has come into contact with. It is the purpose of the "physical stage" to answer these questions in a systematic way by showing the relationships between the phenomena he has observed, and leading up to others still unknown to him, and in particular to show the qualitative and quantitative effects of various factors on these phenomena. This brings us to the third stage, in which these effects are laid down in precise mathematical form.

This book is intended as a contribution to the second of these three stages. The quotation given above clearly reflects the enormous increase now taking place in the amount of information which must be taken in by the student in the first stage, and the tendency to "philosophizing" which may be observed in many electronics engineers throughout the world *), who feel a need to impose some kind of order on this flood of facts, both for their own sake and for that of the student of electronics.

This search for order lies at the basis of the framework on which this book is written. Starting from the definition of electronics as "the study of all physical phenomena involving electrons (or any other charge car-

*) This same "philosophizing" approach is very evident in, for example, many of the papers by prominent American electronics engineers included in the huge May number of the "PROCEEDINGS OF THE I.R.E." to commemorate the 50th anniversary of "the biggest engineers' society in the world". 
riers)" *), we shall divide all electronic phenomena into three main classes:

1) charging (and discharging) phenomena,

2) excitation (and radiation) phenomena, and

3) ionization and emission phenomena.

In each class, we shall show how tha phenomena in question can be produced and modified by the following forms of energy: mechanical, thermal, chemical, electrical, radiant, atomic, and nuclear.

It is hoped that this novel arrangement of the subject matter will serve three main purposes:

a) to provide teachers of electronics and related subjects with a programme basis which will help them to explain and "place" all electronic applications;

b) not only to give the students some feeling for all the basic phenomena involved in electronic devices which they know and which they will come across in the future, but also to arouse and maintain their interest by showing how these basic phenomena play a part in the most up-to-date electronic devices;

c) but above all to get both teacher and student to think, by showing them the sometimes unsuspected relationships between highly diverse phenomena and applications.

The author is sure that many teachers will be made to think twice on coming across terms in this book whose definition differs somewhat from the "classical" one they are used to from other textbooks; he would however ask them to consider seriously which of the two, the "old" or the "new", is more logical and in better agreement with modern views on energy and matter. It is perhaps fitting to finish by quoting the wise words of Descartes: "In order to reach the truth, you must once in your life rid yourself of all the opinions you have received, and reconstruct all the systems of your knowledge right from their foundations."

J. G. R. Van Dijck

*) This definition, adopted by the Comité Electrotechnique Français among other bodies, is a great improvement on other antiquated definitions which are yet still current, such as that contained in the ASA norm C 42 ("electronics is that branch of science and technology which deals with the conduction of electricity through gases and vacuum"). Such limited definitions, which exclude much that is the proper domain of electronics, cannot but breed confusion and illogicality in the minds of both teacher and student. 


\section{CONTENTS}

Page

PREFACE . . . . . . . . . . . . . . . . . . VII

PART I ENERGY AND MATTER

Chapter 1 THE STRUCTURE OF MATTER . . . . . . . . 3

1.1. What is matter? . . . . . . . . . . . . . 3

1.1.1. Definition . . . . . . . . . . . . 3

1.1.2. States of aggregation . . . . . . . . . . . 4

1.1.3. The divisibility of matter . . . . . . . . . 4

1.1.4. Molecules . . . . . . . . . . . . 5

1.1.5. Atoms . . . . . . . . . . . . . . . . 6

1.1.6. Atomic structure . . . . . . . . . . . 7

1.1.7. Empty and yet solid . . . . . . . . . . . . . 8

1.1.8. Electron . . . . . . . . . . . . . . 9

1.1.9. Summary . . . . . . . . . . . . . 10

1.2. Internal structure of the atom . . . . . . . . . . 10

1.2.1. Mass of nucleus and electron . . . . . . . . 10

1.2.2. The electron as unit of charge . . . . . . . 11

1.2.3. Energy and charge . . . . . . . . . . . 11

1.2.4. Protons and neutrons . . . . . . . . . . 12

1.2.5. The periodic table of the elements . . . . . . 13

1.2.6. Radioactivity . . . . . . . . . . . 14

1.2.7. Electron configuration . . . . . . . . . . 16

1.2.8. Chemical reaction . . . . . . . . . . 18

1.2.9. Metals . . . . . . . . . . . . . . 18

1.2.10. Bonds . . . . . . . . . . . . . . . . . . . 19

1.2.11. Difference between these two types of bond . . 19

1.2.12. The crystalline structure of matter . . . . . 20

List of the most important definitions . . . . . . . . 24

Short bibliography (to Part I, chapter 1) . . . . . . . 27

Chapter 2 THE MAIN FORMS OF ENERGY . . . . . . . . $\quad 29$

2.1. What is energy? . . . . . . . . . . . . . . . 29

2.1.1. Importance of the concept of energy . . . . 29 
2.1.2. Definition . . . . . . . . . . . . 30

2.1.3. Energy and matter . . . . . . . . . . 30

2.1.4. Principle of conservation of energy . . . . . 31

2.2. Various forms of energy . . . . . . . . . . 31

2.2.1. Energy equivalents . . . . . . . . . . . 31

2.2.2. Energy bound to matter and energy free from matter . . . . . . . . . . . . . . 32

2.2.3. Kinetic and potential energy . . . . . . . 32

2.2.4. Divisibility . . . . . . . . . . . . 32

2.2.5. Survey of the various forms of energy . . . . 33

2.2.6. Mechanical energy . . . . . . . . . . 34

2.2.7. Thermal energy . . . . . . . . . . . 35

2.2.8. Chemical energy . . . . . . . . . . 36

2.2.9. Electrical energy . . . . . . . . . . 37

2.2.10. Radiant energy . . . . . . . . . . . 38

2.3. Energy and force. . . . . . . . . . . . . . . 44

2.3.1. Equilibrium . . . . . . . . . . . . . . 44

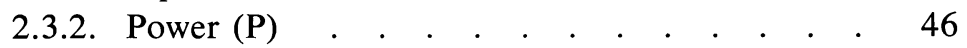

2.3.3. Classification of natural forces . . . . . . . 48

List of the most important definitions . . . . . . . . . 51

Relationship between the various energy units . . . . . 55

Survey of the main forms of energy . . . . . . . . . 56

Brief bibliography (to part I, chapter 2) . . . . . . . . . 58

PART II ELECTRONIC PHENOMENA . . . . . . . . . . 59

INTRODUCTION . . . . . . . . . . . . . . . 61

1. Charging phenomena . . . . . . . . . . . . 61

2. Excitation phenomena . . . . . . . . . . . . 61

3. Ionization phenomena . . . . . . . . . . . . . 62

4. Emission phenomena . . . . . . . . . . . . 62

Chapter 3 CHARGING AND DISCHARGING PHENONEMA . 63

3.1. Charging phenomena . . . . . . . . . . . 63

3.1.1. Principle . . . . . . . . . . . . . 63

3.1.2. Survey of charging phenomena . . . . . . 65

3.2. Voltage sources and transducers . . . . . . . . . 81

3.2.1. Classification of voltage sources . . . . . . . 82

3.2.2. Electronic transducers . . . . . . . . . . 93 
3.2.3. Applications in chemical analysis . . . . . 98

3.3. Discharge phenonema . . . . . . . . . . . 100

3.3.1. The electric current . . . . . . . . . . 100

3.3.2. The various discharge media . . . . . . . 101

3.3.3. Various discharge currents . . . . . . . 116

3.3.4. Secondary discharge phenomena . . . . . 122

List of the most important definitions . . . . . . . . . 146

Table 3.1. Charging phenomena . . . . . . . . . 153

Table 3.2. Discharge processes . . . . . . . . . . . 157

Table 3.3. Effects of discharge processes . . . . . . . 161

Units of charge and related quantities . . . . . . . . . . 162

Chapter 4 EXCITATION AND RADIATION . . . . . . . 163

4.1. Closer study of the structure of the atom . . . . . . . . 164

4.1.1. Energy levels . . . . . . . . . . . 164

4.1.2. Quantum numbers . . . . . . . . . . 164

4.1.3. Pauli exclusion principle . . . . . . . . . 165

4.1.4. Ground state . . . . . . . . . . . . 165

4.1.5. Excitation energy . . . . . . . . . . 165

4.1.6. Electromagnetic radiation . . . . . . . 167

4.1.7. Spectral lines . . . . . . . . . . . . 167

4.2. Light from electrons . . . . . . . . . . . . 168

4.2.1. Line spectrum . . . . . . . . . . . . . 168

4.2.2. Characteristic spectral lines . . . . . . . . . 169

4.2.3. An excited atom can behave in three different
ways . . . . . . . . . . . . . 171

4.3. How is an atom excited? . . . . . . . . . . 173

4.3.1. Principle . . . . . . . . . . . . . . . 173

4.3.2. Survey of methods of excitation and their effects 174

4.4. The complete electromagnetic spectrum . . . . . . 178

4.4.1. Complete spectrum . . . . . . . . . . . 178

4.4.2. Radio spectrum . . . . . . . . . . . 178

Survey of the radio spectrum . . . . . . . . . . . . 179

4.5. Radiation sources . . . . . . . . . . . . 188

4.5.1. Principle . . . . . . . . . . . . . . 188

4.5.2. Survey . . . . . . . . . . . . . . . 188

4.6. Some of the main applications . . . . . . . . . . 192

4.6.1. From atomic clock to "maser" . . . . . . 193 
4.6.2. Maser . . . . . . . . . . . . . . 194

4.6.3. Laser (optical maser) . . . . . . . . . . 195

4.6.4. New unit of length . . . . . . . . . . . . 198

4.6.5. Modern light sources . . . . . . . . . 198

4.6.6. Luminophores (phosphors) . . . . . . . . 206

4.6.7. Material testing by means of luminescence . . . 207

4.6.8. Material testing with X-rays . . . . . . . 207

4.6.9. Gamma-radiography . . . . . . . . . 211

List of the most important definitions . . . . . . . . 212

Table 4.1. Excitation and radiation phenomena . . . . . 215

Table 4.2. Radiation processes . . . . . . . . . . 219

Table 4.3. Various effects of radiation phenomena . . . . 223

Excitation and radiation . . . . . . . . . . . . 226

Chapter 5 IONIZATION AND EMISSION PHENOMENA . . . 228

5.1 Ionization potential and work function . . . . . . 228

5.1.1. Definition . . . . . . . . . . . . 228

5.1.2. Ionization potential . . . . . . . . . 230

5.1.3. Ionization potential as a function of the atomic number . . . . . . . . . . . . . 230

5.1.4. Role of the boundary layer . . . . . . . . 230

5.1.5. Conduction-band potential . . . . . . . . 231

5.1.6. Stimulating emission . . . . . . . . . 233

5.1.7. Contact potential and work function . . . . . 234

5.1.8. Metal and semiconductor . . . . . . . . 235

5.1.9. Two semiconductors . . . . . . . . . . 237

5.1.10. Rectification effect . . . . . . . . . . 238

5.2. Survey of emission phenomena . . . . . . . . . 240

5.2.1. Emission caused by mechanical energy . . . . 240

5.2.2. Emission due to heating the cathode material . . 240

5.2.3. Chemical emission . . . . . . . . . . 248

5.2.4. Emission under the influence of strong electric fields (field emission or cold emission) . . . . . 249

5.2.5. Emission under the influence of light (photoelectric emission) . . . . . . . . . . . 251

5.2.6. Emission produced by bombardment with elementary particles . . . . . . . . . . 254

5.2.7. Emission produced by nuclear energy . . . . 259

5.3. Elementary-particle sources . . . . . . . . . 259 
5.3.1. Electron sources . . . . . . . . . . . 260

5.3.2. Ion sources . . . . . . . . . . . . . 261

5.3.3. Neutron sources . . . . . . . . . . . . 263

List of the most important definitions . . . . . . . . 264

Table 5.1. Ionization and emission phenomena . . . . . 267

Table 5.2. Emission processes . . . . . . . . . . 270

Table 5.3. Various effects of electron beams . . . . . . 272

PART III ELECTRON TUBES AND SOLID STATE DEVICES 275

Chapter 6 ELEMENTS OF ELECTRON OPTICS . . . . . . 277

6.1. The double nature of electron . . . . . . . . . . . 277

6.1.1. The electron as charge carrier and little magnet 277

6.1.2. Particle and waves aspects . . . . . . . . . . 278

6.1.3. Light beams and electron beams . . . . . . 278

6.1.4. Deflection . . . . . . . . . . . . 279

6.2. Basic electron optics . . . . . . . . . . . . . . . 279

6.2.1. Definition . . . . . . . . . . . . 279

6.2.2. Behaviour of the electron in an electric field . . 279

6.2.3. Non-homogeneous field . . . . . . . . 281

6.2.4. Behaviour of the electron in a magnetic field . . 281

6.2.5. Light optics and electron optics . . . . . . 282

6.2.6. Electric lenses . . . . . . . . . . . 285

6.2.7. Magnetic lenses . . . . . . . . . . . 286

6.3. Some practical applications . . . . . . . . . . . . . . 287

6.3.1. The control of the electron current in vacuum tubes . . . . . . . . . . . . . . 287

6.3.2. Velocity-control . . . . . . . . . . . 291

6.3.3. Travelling wave tubes . . . . . . . . . . . 292

6.3.4. Tetrode principle (electron acceleration) . . . 293

6.3.5. Electron accelerators . . . . . . . . . 294

6.3.6. Focussing of electron beams by continuous electri cand magnetic fields . . . . . . . 295

6.3.7. Electron telescope . . . . . . . . . . 296

6.3.8. Electron microscope . . . . . . . . . . . . 297

6.3.9. Electron-diffraction camera . . . . . . . 301

List of the most important definitions . . . . . . . . 304

Chapter 7 INTRODUCTION TO THE STUDY OF ELECTRON DEVICES . . . . . . . . . . . . . . 306 
7.1. Introduction . . . . . . . . . . . . . . 306

7.1.1. Principle and definition . . . . . . . . 306

7.1.2. Various control methods . . . . . . . . 307

7.2. Survey of the most important electron devices . . . . 307

7.2.1. Intensity devices . . . . . . . . . . . 307

7.2.2. Electron-beam devices . . . . . . . . . 312

7.2.3. Velocity-modulated devices . . . . . . . 315

7.2.4. Kinenergetic devices (accelerators) . . . . . 317

7.2.5. Electron devices for special purposes . . . . 322

7.3. The six main functions of electron devices . . . . . 323

7.3.1. Rectification . . . . . . . . . . . . 324

7.3.2. Switching (and relay function) . . . . . . . $\quad$. 327

7.3.3. Amplification . . . . . . . . . . . 330

7.3.4. Oscillation . . . . . . . . . . . . 340

7.3.5. Radiation . . . . . . . . . . . . 346

7.3.6. Memory . . . . . . . . . . . . . 348

List of the most important definitions . . . . . . . . . 354 INDEX . . . . . . . . . . . . . . . . . . . 357 